\title{
Biotechnology to fight bioterrorism
}

\author{
While the fight against terrorism is helping to revitalize the biotech market, academic scientists are starting to \\ worry about limitations on research
}

I $\mathrm{n}$ the first week of this year, British police arrested six North Africans after finding traces of a deadly toxin, ricin, in their London apartment. The British subsequently stepped up their domestic fight against terrorism, taking the unprecedented step of storming a mosque in central London, arresting seven men there, and three more in Manchester. Ricin, a natural plant toxin, was developed as a bioweapon by the Soviet secret service during the Cold War, and was used by their Bulgarian cohorts to kill the dissident Georgi Markov in 1978. It is not an ideal weapon of mass destruction, but its discovery in London has sparked fresh concerns about bioterrorism in Europe and the USA. Indeed, while the UN (United Nations) weapons inspectors in Iraq were searching for weapons of mass destruction early this year, the US government intensified its measures against bioweapons, with serious implications for science, public health and industry.

The possibility that Iraq has biological weapons and might use them in the event of an invasion, or give them to terrorists, is of great concern. "Due to Iraq's skill in frustrating and deceiving UN arms inspectors [...] and given that since 1998 it escaped inspections altogether, no outside party currently knows the precise state of Iraq's chemical, biological, nuclear and radiological effort," Avigdor Haselkorn, a strategic analyst, wrote recently in Biosecurity and Bioterrorism (1; 2003). "But it is certain that, given its interest in a secret strategic weapon capacity, biological weapons figure prominently in the Iraqi plan. Of all the various weapons of mass destruction, biological weapons are the most prone to concealment, clandestine transportation, and effective covert employment," he added. Possible pathogens that Iraq is believed to harbour include anthrax, smallpox, tularaemia, typhoid, yellow fever, the
Ebola and Marburg viruses, botulism and plague. A recent report by the US Department of Defense also hypothesizes that bioweapons are among the few capabilities that Iraq has improved on since its defeat in the 1991 Gulf War. And the USA is ill-prepared to respond to an attack with any of these agents-the anthrax cases after 11 September 2001 showed that just a few letters are sufficient to close down government and postal offices and create panic among the population.

\section{The anthrax scare and smallpox vaccinations are drawing resources away from the treatment of tuberculosis and other infectious diseases}

The response in the USA and other countries after the anthrax mailings was swift, but not particularly effective- the perpetrator has not yet been found. Nevertheless, the US government allocated $\$ 2.7$ billion- $\$ 1$ billion from the Department of Defense and $\$ 1.7$ billion from the National Institutes of Health (NIH) — for the fight against terrorism, and the Homeland Security Act was passed to increase and co-ordinate protection against terrorist attacks. More recently, US President George W. Bush allocated $\$ 6$ billion over the next decade for a biodefence programme called Project Bioshield. However, there is a dearth of effective antibiotics for bioweapons, inadequate quantities of smallpox vaccine, and there are no vaccines or other drugs to counteract the effects of botulinum toxin, the Ebola and Marburg viruses, and many other pathogens. In January this year, Erik Henchal, a high-ranking officer in the US Army Medical Research Institute of Infectious Diseases (USAMRIID) in Fort Detrick, MD, gave a scalding press interview in which he said that the US government has insufficient vaccines to protect its troops from anthrax and smallpox, because biotech companies have no financial incentive to produce them and the army itself will not pay for their development. Clearly, soldiers are the most at risk. The ability to detect bioweapons in the battlefield is minimal to nonexistent, and diagnosis in general is too slow. The protective gear for soldiers is largely ineffective against weaponized pathogens, some of which exist in particles that are so small that they can penetrate the material. There are also problems with the existing anthrax vaccine. Some Gulf War veterans believe it caused disabling neurological side-effects in as many as $30 \%$ of those who received it, and further research indicates that a combination of vaccines, pesticides and burning oil fumes may have caused neurological damage.

$\mathrm{n}$ late January this year, the US government announced the establishment of a surveillance network to be implemented by the Centers for Disease Control and Prevention (Atlanta, GA, USA). It will monitor, collect and analyse health data in eight major US cities, and will replace an earlier Pentagoncoordinated system that raised the hackles of many concerned about privacy. "The [...] initiative represents a sharp swing to civilian leadership in a field the military pioneered and once dominated. But even in civilian hands, the emerging network has raised concerns that such surveillance may violate individual medical privacy rights," William Broad and Judith Miller wrote in The New York Times on 27 January 2003.

Last June, the US Food and Drug Administration said that it would approve additional drugs and vaccines to combat bioterrorism based only on animal data, which worries some. Bioweapons research "has created an 


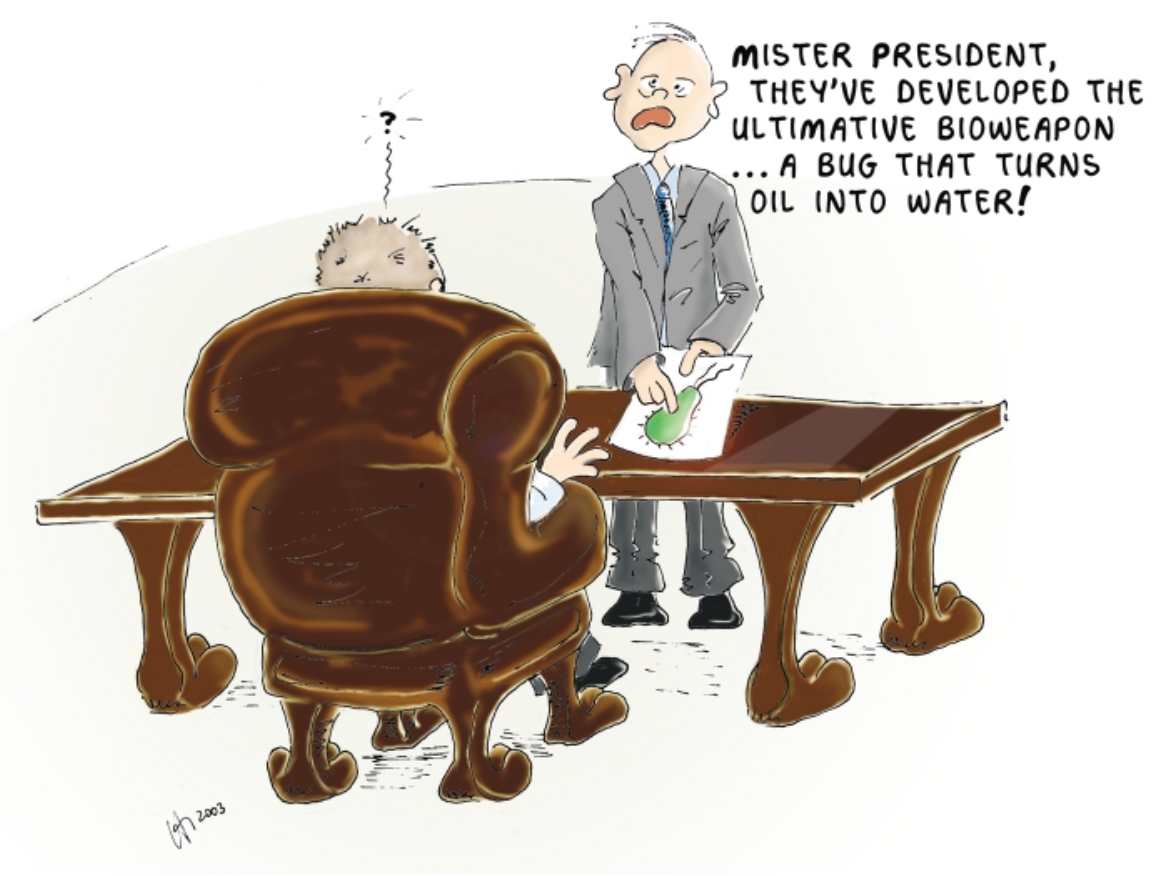

important but little-discussed ethical challenge," bioethicists Arthur Caplan and Pamela Sankar, from the University of Pennsylvania (Philadelphia, PA, USA), commented in Science (298, 923; 2002). If human testing on new vaccines does occur, some injury is likely, which challenges the medical ethics of 'do no harm,' they note. Therefore, there is a need for clear guidelines to establish "its [bioweapons'] unequivocal relevance to national security concerns." The picture is even more complicated, because, according to the Homeland Security Act, vaccine and drug manufacturers will not be liable for damages caused by any new drugs that are developed.

On the home front, a potential attack with smallpox or anthrax is the greatest concern, so President Bush announced a three-step plan in December 2002 that calls for up to 500,000 health workers to be vaccinated with the available smallpox vaccine, followed by up to 10 million citizens in two further steps. But the use of this vaccine is controversial; experts are concerned with the safety of first-generation vaccines, which can cause one to two deaths per million vaccinations. Furthermore, the attenuated virus in the vaccine can still be transmitted through skin contact, and can cause serious side-effects among those who are immunocompromised, take immunosuppressive medication or suffer from eczema or atopic dermatitis. A 15member panel from the Institute of Medicine thus recommended taking more time between the first and the second phase of vaccine development so that more safeguards can be put in place. Another problem with US biodefence is that funds that are usually devoted to public health projects are now being diverted. The anthrax scare and smallpox vaccinations are drawing resources away from the treatment of tuberculosis and other infectious diseases.

$$
\text { T }
$$
'he good news is that, during the past 18 months, the private sector has started to fill in what Henchal (USAMRIID) called the holes in biodefence. According to the Biotechnology Industry Organization, between 75 and 100 companies are now involved in research on bioterrorism, applying their technologies to drug and vaccine development. Cubist Pharmaceuticals (Lexington, MA, USA), for instance, is using its Vita validation technology, high-throughput screening and structural biology facilities to develop new antibiotics; Vical (San Diego, CA, USA) is using its 'naked DNA' technology in the development of new vaccines, and Gilead Science's (Foster City, CA, USA) antiviral drug, cidofovir, approved in 1996 for hepatitis $\mathrm{B}$, is now being tested as a treatment for adverse reactions to the smallpox vaccine used at present. VaxGen (San Francisco, CA, USA), known for having an HIV vaccine in advanced clinical trials, is now joining forces with the Japanese company Kaketsuken (Kumamoto, Japan), which in the 1970s developed a smallpox vaccine used to vaccinate approximately 50,000 Japanese children. VaxGen expects that its new smallpox vaccine will be launched in 2004.

Bavarian-Nordic (Copenhagen, Denmark) already has two second-generation smallpox vaccines on the market, which were administered to more than 150,000 people during the 1970s without serious side-effects. The company has shipped thousands of doses to Germany and Greece for military use, and the German government has ordered another 11 million, with the aim of stockpiling 100 million doses of the vaccine by the end of this year. Bavarian-Nordic also launched its studies of a third-generation smallpox vaccine, Modified Ankara Vaccine-Bavarian-Nordic (MVA-BN), in Europe in February 2001. This vaccine was well-tolerated, and can be given to the immunocompromised, unlike the firstand second-generation vaccines. American Biogenetic Sciences (Copiague, NY, USA) is seeking a partner to test an oral smallpox vaccine based on Russian research. Therion Biologics (Cambridge, MA, USA) recently began a phase I trial with the US National Institute of Allergy and Infectious Disease to test its MVA vaccine, and Acambis (Cambridge, UK) has completed its own phase I and II trials of two smallpox vaccines. Siga Technologies (New York, NY, USA) is developing an antiviral drug, which targets a specific enzyme necessary for viral reproduction, for those who cannot be vaccinated.

Anthrax is also high on the target list for biotech companies. The current vaccine must be given in 6 injections over 18 months, then boosted yearly - an impractical strategy for the armed forces. Avant Immunotherapeutics (Needham, MA, USA) and its partner DynPort Vaccine Company LLC (Reston, VA, USA) recently started a phase I trial of its second-generation vaccine for the US Department of Defense. This vaccine consists of a highly purified recombinant version of the protective antigen of anthrax, and requires only a single administration. In late January, Avant won a contract to develop a third-generation oral combination-vaccine against anthrax, cholera and plague, which will hopefully confer immunity in days rather than weeks. It is also developing separate vaccines for cholera and typhoid.

...Lewis Branscom from Harvard University [...] fears that barring certain individuals from research is reminiscent of 'witch-hunts' during the McCarthy era 
The chief scientist at Hadron Advanced Biosystems (Alexandria, VA, USA) is Ken Alibek, the former second-in-command of Russia's bioweapons project, who defected to the USA in 1992. He has discovered two ways to block anthrax in its later stages. One is to inhibit anthrax's protective antigen; the other is to block the bacterium's second punch, the lethal factor protein, one of two crucial infective parts of the bacterium, from causing its toxic effects. In addition, Hadron has identified an antibiotic that has greater activity against the bacterium than the current first-line antibiotics, and has further identified five haemolytic Bacillus anthracis proteins that, when inactivated, prevent a productive infection from becoming established. Xenerex Biosciences (San Diego, CA, USA), a subsidiary of Avanir, is developing neutralizing human antibodies to reduce the post-exposure damage caused by anthrax. Similarly, EluSys (Pine Brook, NJ, USA) is collaborating with the University of Texas in Austin, USA, and USAMRIID to develop heteropolymers to remove anthrax toxin from the bloodstream. The EluSys technology uses two monoclonal antibodies that are chemically linked, like a biological double-sided sticky tape. One antibody binds to the target to be removed - the anthrax toxin-and the second binds to a receptor on red blood cells, which then carry the pathogen to the liver to be destroyed. EluSys' first heteropolymer was tested last year in lupus patients, and chief executive officer Steven Sudovar believes that this technology could be used to treat other blood-borne viruses, bacteria, toxins and autoantibodies.

Biotech companies' efforts are also focusing on other pathogens: GenPhar (Mount Pleasant, SC, USA) is developing a multivalent vaccine against Marburg virus that was shown to produce neutralizing antibodies and cytotoxic $\mathrm{T}$ lymphocyte responses in animals. ID Biomedical (Vancouver, Canada) recently reported encouraging preclinical results with a proteasome-based plague vaccine: immunized mice developed high levels of antibodies in blood and respiratory fluids, and showed a high degree of protection against aerosoladministered plague. Hematech (Sioux Falls, SD, USA), supported by a $\$ 3.3$ million US government grant, is working on a bovine transgenic system for producing human polyclonal antibodies against botulinum neurotoxins.
A Ithough the US government's fight against bioterrorism is already helping to revitalize a depressed biotech market, others are not particularly happy with its effect on the way scientific research is carried out and made public, and, more importantly, which scientists are allowed to work in the USA. More than 60 substances that could potentially be used to create biological weapons have been given restricted-use status, and no scientist with a history of mental illness, drug conviction or from a nation considered to be a sponsor of terrorism can work with these materials. Scientists are concerned about these limitations made in the name of national security: The New York Times cited Lewis Branscom from Harvard University, who fears that barring certain individuals from research is reminiscent of 'witch-hunts' during the McCarthy era. The US National Academy of Science (NAS) issued a statement that "recent efforts by our government to constrain the flow of international visitors in the name of national security are having serious, unintended consequences for American science, engineering and medicine". And, in January, the NAS sponsored a meeting between scientists and security officials to discuss the censorship of data and restrictions on research. Meanwhile, George Poste, former head of R\&D at GlaxoSmithKline (Brentford, UK) and Chair of the US Department of Defense's Task Force on Defense Against Bioterrorism, emphasized the special dangers of 'dual use' technology - that which can be used both for drug development and to produce bioweapons. Gigi Kwik, of the Johns Hopkins Center for Civilian Biodefense Strategies (Baltimore, MD, USA), noted in Biosecurity and Bioterrorism $(\mathbf{1} ; 2003)$ that guidelines are being prepared to enable researchers to publish their work without giving away information that could be useful to a bioterrorist. But, although terrorists could potentially make use of public genome sequences, Claire Fraser, Director of the Institute for Genomic Research (Rockville, MD, USA), maintained that such sequences should remain in the public domain because these 'maps' are still relatively rough. Genomics should be used to identify and fight bioterrorism, not to restrict research, she said.

\section{Vicki Brower}

doi:10.1038/sj.embor.embor783

\title{
Feeding prejudice
}

\author{
Reluctance within the European Union to accept genetically modified \\ crops may hinder the benefits of this technology reaching the \\ developing world
}

T he words "impractical and unenforceable" were used by the European food and drink association, the CIAA, to greet the European Union (EU) legislation on the labelling of genetically modified (GM) food that is likely to become law later this month. The new ruling requires that all foods containing more than $0.5 \%$ GM produce are labelled as such. Controversially, the ruling extends this to all highly processed products derived from GM crops that no longer contain any traces of the dubious GM DNA or protein, such as oils. Critics fear that this will lead to an unnecessary paper trail for these goods, which is open to fraud and abuse as it cannot be based on simple detection methods. Although this may eventually lead to a lifting of the current EU ban on GM products imported from the USA, it will be a logistical nightmare for US producers as around $70 \%$ of the soybean and $30 \%$ of the maize that they grow is genetically engineered, and no such labelling of their downstream products is required. Not surprisingly, the USA are becoming increasingly frustrated with this cautious EU attitude, and it has caused further deterioration in what were already strained trade relations.

These new labelling laws are being hailed as a victory for the European consumer after numerous scare stories about GM crops. The flames of societal anxiety that these have created have been fanned by a prevailing wind of negative opinion 